\title{
Butterfly ranching: sustainable use of insects and sustainable benefit to habitats
}

\author{
T. R. New
}

Butterfly ranching is an important facet of promoting habitat conservation in tropical regions. Recent developments, emphasizing centralized co-ordination of rural cottage industries, are summarized to indicate progress in integration of trade and larger scale species and habitat sustainability.

\section{Introduction}

The greatest threat to butterfly well-being, as for many other organisms, is alienation or destruction of habitat (New, 1991). However, butterflies are relatively unusual among invertebrates in that they have long been sought by collectors, and 'over-collecting' has often been advanced as a contributory cause of decline. In general, this claim is false and collecting per se is only rarely a serious threat to butterflies. As with other collectables, rare butterflies can command high prices. One drawback of legislation prohibiting collecting of butterflies has been to increase the cash value of rare taxa on the black market, and to increase unscrupulous attempts to obtain these with little regard for their conservation. However, it is now becoming recognized that this demand for dead insects, including the rarest taxa (some listed on Appendix I, which bans commercial trade, or Appendix II, which controls and monitors trade, of the Convention on International Trade in Endangered Species of Wild Fauna and Flora - CITES), may be harnessed as an important tool for butterfly conservation and the sustainability of tropical forest habitats.

Commercial demands may be met by controlled rearing of butterflies, predominantly through 'ranching' (whereby unenclosed habitat patches are enriched with larval foodplants and adult nectar sources and thereby rendered superattractive, and from where specimens may be harvested by rearing from collected early stages) but also through the more expensive 'farming' (involving enclosure of butterflies in cages for rearing offspring from captive colonies). Ranching has practical advantages because the low capital outlay enables people to participate easily. Both methods allow the proprietor to obtain reared specimens in perfect condition, and elusive sexes of some species - which may be caught only with difficulty in the wild - for sale to collectors without further intrusion into wild populations. Development of such operations can also help to reduce destruction of primary habitat by lessening economic dependence on shifting agriculture as a result of cash being available from sales of insects, and furnish supplies for translocation or augmentation of sparse natural populations.

This report summarizes some recent trends in butterfly breeding as a facet of conservation management, emphasizing the role of butterflies as a harvestable sustainable resource. Morris (1993) suggested that the butterfly resource' in Europe is no longer self-perpetuating and needs to be managed in detail if it is to survive, and that emphasis on butterflies as a resource underlies both use and conservation. Especially in the less developed parts of the world, 'sustainable use' may be the avenue through which conservation of butterflies can be pursued most effectively. Even though cash may not flow directly to conservation activities, promoting trade in butterflies can assist substantially in conserving and enriching habitats for butterflies and many less conspicuous animals. 


\section{Butterfly trade and rearing: practice, problems and conservation}

The public appeal of butterflies manifests in several ways.

1. Their use in deadstock trade, ranging from high-priced individual rarities for collectors (low-volume trade, but high-quality specimens needed) to bulk sales as souvenirs and ornaments (high volume, medium quality and low unit price) (Collins and Morris, 1985).

2. Their appeal as live exhibits in butterfly houses and similar establishments (Collins, 1987), necessitating regular supplies of livestock (most commonly as pupae) as a trade involving relatively common, showy, long-lived species.

3. Their appeal in the wild to tourists, so that 'butterfly safaris' and similar tours are increasing in popularity and more specialized collecting or photographic tours are advertised regularly in magazines read by collectors and naturalists.

There are, therefore, clear economic benefits, which centre on the butterfly faunas of tropical regions - in general, those parts of the world where the temperate region approach of 'species-focusing' for conservation is not widespread, where threats to major habitats are great, and where human per capita income is low and overseas dollars may be a significant income component. The National Research Council (1983) noted that the Papua New Guinea butterfly farming (technically, ranching) operation, which was started through the government's Insect Farming and Trade Agency (IFTA) and which then involved some 500 people in many parts of the country, led to people participating in a cash economy for the first time in their individual and cultural history. The recent Action Plan for swallowtail butterflies (New and Collins, 1991) suggested the need for similar operations as conservation tools in some other parts of the world, and stressed the practical integration of in situ and ex situ conservation measures for butterflies; the latter must not be allowed to replace the former, and strenuous efforts to conserve and manage habitats sustainably will always be needed. Examples from other parts of the world also demonstrate how business in butterflies can promote conservation by providing a rationale for local people to protect rain-forest habitats (Costa Rica: Bronaugh, 1993). There is a clear negative relationship between levels of affluence and need to use butterflies: the bulk deadstock trade in Taiwan, for example, has declined markedly as living standards have risen there.

The IFTA in Papua New Guinea sells insects worth approximately $\$$ US400,000 annually to collectors (Orsak, 1993), with ranched birdwing butterflies comprising a high proportion of this; the Agency's activity and responsibilities were reviewed recently by Clark (1992) and Clark and Landford (1992). The desire for dead butterflies by collectors is an integral part of practical conservation, and is satisfied by harvesting ranched populations. Orsak stressed the high priority of meeting human needs rather than promoting wildlife aesthetics and that 'conservation through development' is a far better way to protect wildlife in poorly developed areas. In terms of resulting individual incomes, Orsak (1993) quoted sustainable annual incomes of perhaps K50-200 (K1 = \$US1) for insect collecting, and $\mathrm{K} 100-500$ for an established butterfly ranch. Higher incomes have been documented, and such figures are around the minimal rural wage of about K1000/year - but only about 15 per cent of the population is employed formally (Orsak, 1993). Incomes have risen steadily, reflecting increase in world prices and improvement in quality of insects received from experienced ranchers. Mercer and Clark (1989) stated that incomes of K2000-K3000 are quite common for butterfly farmers in island locations or the Papua New Guinea highlands.

Forest species tend to be rarer than most disturbed-habitat butterflies, and command higher prices; their sustainability provides incentive to promote forest protection. Similarly, butterflies of other susceptible habitats, such as isolated islands, may be expensive because they are localized subspecies or races desired by collectors (Orsak, 1993). Orsak's message 'killing butterflies to save butterflies is the lesson of effective wildlife conservation in the 
Third World today' reflects that, without expansion of the deadstock trade as a source of income, the alternative may well be to continue to exploit forests non-sustainably to the detriment of the whole natural community. There are thus clear links between controlled ranching and harvesting of butterflies, using an artificially created excess, and benefits to both the individual rancher and to the natural world through increased sustainability. Neville (1993) stressed that the management and marketing agency must also be sustainable.

In Papua New Guinea, the key seems to be the centralization of the industry, with necessary CITES and export permits provided at source. One practical problem of such centralized operations is maintaining effective control so that smuggling or black market operations are eliminated. The Irian Jaya operation (Neville, 1992, 1993) in the Arfak Mountains (as part of the conservation strategy for the Arfak Mountains Natural Conservation Area: Craven and de Fretes, 1987), for example, long lacked a general export permit from the Indonesian Government, and obtaining such a permit for an insect farming enterprise in southern China also proved protracted. Such delays lead to lack of confidence among village butterfly farmers, who may sell stock to illegal traders for an 'easy' return; sometimes their traditional sources of income but now involving greater volumes/numbers of insects from ranching. This thereby enhances the role of middlemen, some of dubious integrity, whose participation centralized operations are intended (in part) to eliminate.

There is potential for further operations modelled on the IFTA scheme, perhaps particularly in the Indo-Australian region (Parsons, 1992). The livestock trade needs continuing, sustainable supply (Collins, 1987) and all (or almost all) temperate region butterfly houses import most of the tropical stock they exhibit. Many have adjunct souvenir shops and the like, which could be fostered more effectively as conduits of information on butterflies and their conservation needs. Live exhibits in the tropics are perhaps especially important in fostering conservation goodwill both to local people and tourists. The Penang butterfly farm, Malaysia, produces an informative guide (Khoo and Chng, 1987), which is a model of its type, illustrating and providing biological information on many of the species displayed.

The practical knowledge gained by managers of butterfly houses in the tropics while rearing their exhibition stock will usually have elements of original discovery, in some cases pioneering or refining sustainable rearing of particular taxa. Such knowledge is directly relevant to conservation programmes involving ex situ rearing to build up stock for eventual release to the wild. Local education, both in the practice of ranching (see Parsons, 1978) and in the wider conservation aspects of this is needed so that ranching and trading operations can truly involve local communities rather than be seen as exploitative, non-sustainable and/or dominated by ex-patriate interests.

Despite the premium placed on prime-quality reared butterflies, collected specimens may be important in augmenting project income (Parsons, 1992): some local endemic taxa may be netted or bait-collected more easily than they could be ranched, and listing of such species on sales lists (even if as slightly defective) may increase interest and funding. Indeed, many taxa desirable to collectors cannot be ranched at present. Monitored and controlled collecting may also be an important facet of promoting ecotourism. Diversity of activities may thus promote conservation and local sustainability; in addition to butterflies, large and showy moths, beetles, grasshoppers, stick insects, mantids and others are sought by collectors and tourists alike, and most of these are not yet amenable to ranching or farming. Many are also quite abundant, and sustainable harvesting - perhaps based on quotas - is realistic. Ranchers and collectors in Papua New Guinea are recommended to take only a proportion of catchable butterflies and not to risk over-collecting at rich sites.

Advocacy for trade in dead butterflies may seem an 'odd' conservation message! Clearly, over-exploitation of rare species could occur under some circumstances, and the vast volume of unregulated trade in butterflies gives 
cause for serious appraisal and concern. However, Orsak's (1993) comment that the legal trade in birdwings and other insects is essential for the survival of those species, and for the sustainability of the primary forest habitats inhabited by so many invertebrates, is a message of much wider relevance in helping to counter the massive environmental degradation occurring over so much of the tropics, through centralized control of a sustainably harvestable resource.

\section{Acknowledgement}

I am very grateful to Dr A. L. Yen for his critical comments on a draft of this note.

\section{References}

Bronaugh, W. 1993. Farming the flying flowers. Wildlife Conservation (September/October), 54-62.

Clark, P.B. 1992. Organization and economics of insect farming. [Paper read at Invertebrates (Microlivestock) farming seminar, La Union, Philippines, November 1992.]

Clark, P.B. and Landford, A. 1992. Farming insects in Papua New Guinea. International Zoo Yearbook, 30, 127-131.

Collins, N.M. 1987. Butterfly Houses in Britain. The Conservation Implications. IUCN, Gland.

Collins, N.M. and Morris, M.G. 1985. Threatened Swallowtail Butterflies of the World. IUCN, Gland.

Craven, I. and de Fretes, Y. 1987. Arfak Mountains Nature Conservation Area, Irian Jaya. Management Plan 1988-1992. WWF Project No. 3770.

Khoo Su Nin and Chng, W.W. 1987. Penang Butterfly Farm Guide Book. Yeoh Teow Giap, Penang.

Mercer, C.W.L. and Clark, P.B. 1989. Organization and Economics of Insect Farming in Papua New
Guinea. Proceedings 1st Symposium of Papua New Guinea Society of Animal Production (Smallholder Animal Production in Papua New Guinea), 62-70.

Morris, M.G. 1993. Europe's butterflies; conserving a cultural and scientific resource. In Future of Butterflies in Europe (eds T. Pavlicek-van Beek, A. H. Ovaa and J. G. van der Made), pp. 4-14. Agricultural University, Wageningen.

National Research Council 1983. Butterfly Farming in Papua New Guinea. Managing Tropical Animal Resources Series. National Academy Press, Washington DC.

Neville, D. 1992. Butterfly Farming in the Arfak Mountains of Irian Jaya, a Project Update. WWF, Manokwari

Neville. D. 1993. Butterfly farming as a conservation tool: lessons learnt during implementation of butterfly farming in the Arfak Mountains, Irian Jaya. (Paper read at International Butterfly Conference, Ujung Pandang, Indonesia, August 1993).

New, T.R. 1991. Butterfly Conservation. Oxford University Press, Melbourne.

New, T.R. and Collins, N.M. 1991. Swallowtail Butterflies. An Action Plan for their Conservation. IUCN, Gland.

Orsak, L. 1993. Killing butterflies to save butterflies: a tool for tropical forest conservation in Papua New Guinea. News Lepidopt. Soc. May/June 1993, 71-80.

Parsons, M.J. 1978. Farming Manual. Insect Farming and Trading Agency. Division of Wildlife, Bulolo, Papua New Guinea.

Parsons, M.J. 1992. The butterfly farming and trading industry in the Indo-Australian Region and its role in tropical forest conservation. Tropical Lepidoptera 3 (Supplement 1), 1-31.

T. R. New, School of Zoology, La Trobe University, Bundoora, Victoria 3083, Australia. 